\title{
PELATIHAN OLAH FOTO DIGITAL UNTUK MENINGKATKAN KEMAMPUAN PESERTA DIDIK DENGAN MENGGUNAKAN APLIKASI ADOBE PHOTOSHOP CS6 PADA LKP BINTANG MULIA BATU BARA
}

\author{
Febby Madonna Yuma*, Juna Eska \\ Program Studi Sistem Informasi, STMIK Royal Kisaran \\ E-mail: febbyyuma@gmail.com*
}

\begin{abstract}
Community service activities entitled "Digital Photographic Training To Enhance Capabilities and Train Students by Using Adobe Photoshop CS6 Applications at LKP Bintang Mulia Batu Pematang Rambai Village, Nibung Hangus District, Batu Bara Regency, North Sumatra". The method used in this activity is a description and practice. Some important points are explained and practiced in this activity, namely increasing the ability to process and edit image or digital photo data, with Adobe Photoshop CS6 software.
\end{abstract}

Keywords: Adobe Photoshop CS6, LKP Bintang Mulia, Digital Photos.

\begin{abstract}
Abstrak: Kegiatan pengabdian kepada masyarakat yang diberi judul "Pelatihan Olah Foto Digital Untuk Meningkatkan Kemampuan dan melatih Peserta Didik Dengan Menggunakan Aplikasi Adobe Photoshop CS6 Pada LKP Bintang Mulia Batu Bara Desa Pematang Rambai Kecamatan Nibung Hangus Kabupaten Batu Bara Sumatera Utara”. Metode yang digunakan dalam kegiatan ini adalah deskripsi dan praktek. Beberapa point penting yang dijelaskan serta dipraktekkan dalam kegiatan ini, yaitu meningkatkan kemampuan mengolah dan mengedit data gambar atau foto digital, dengan perangkat lunak Adobe Photoshop CS6.
\end{abstract}

Kata Kunci : Adobe Photoshop CS6, LKP Bintang Mulia, Foto Digital.

\section{PENDAHULUAN}

Lembaga Keterampilan dan Pendidikan (LKP) merupakan satuan pendidikan luar sekolah (nonformal) yang diselenggarakan bagi warga masyarakat yang memerlukan bekal untuk mengembangakn diri, mengembangkan profesi, usaha mandiri, keterampilan, kecakapan hidup, bekerja mencari nafkah, dan melanjutkan ke tingkat atau jenjang pendidikan yang lebih tinggi. Lembaga Keterampilan dan Pendidikan ( LKP) Bintang Mulia Batu Bara berdiri pada bulan Maret tahun 2018 yang beralokasi di Desa Pematang Rambai Kecamatan Nibung Hangus Batu Bara Sumatera Utara.

LKP Bintang Mulia didirikan 
atas dasar memberikan pelayanan pendidikan kursus komputer baik kepada tingkatan siswa sekolah maupun masyarakat umum yang ingin menambah dan meningkatkan ilmu di bidang ilmu komputer. Lembaga Keterampilan dan Pendidikan (LKP) memiliki dua staff pengajar yang menerima kursus untuk tingkatan SD, SMP, SMA dan Umum. Dengan materi pembelajaran Microsoft Office, Internet, Bahasa Pemograman, Multimedia, serta materi bagaimana menginstalasi hardware atau software dan merakit komputer.

Foto merupakan gambar diam baik berwarna maupun hitam putih yang dihasilkan oleh kamera yang merekan suatu objek atau kejadian atau keadaan suatu waktu tertentu. Foto juga bisa diartikan sebagai citra yang memiliki arti benda buatan manusia, biasanya dua dimensi, yang mempunyai kemiripan dengan suatu objek yang mana biasanya objek-objek fisik atau manusia. Citra dapat ditang-kap dengan alat optic, seperti kamera, cermin, lensa, teleskop, mikroskop, dan sebagainya dan objek atau fenomena alam seperti mata atau permukaan air. Banyak sekali citra dua dimensi, yang berupa foto sekarang mudah dibuat baik menggunakan kamera digital maupun kamera dari Handphone.

Namun seringkali hasil dari foto yang telah di ambil tersebut tidak sesuai dengan keinginan kita, seperti pengambilan gambar terlalu jauh atau dekat, kurang cerah (brightness), kurang tajam warnanya (contras) dan lainnya.
Untuk dapat memperoleh hasil foto atau gambar yang lebih maksimal yang sesuai dengan keinginan, tidak jarang banyak orang yang selalu ingin mengedit foto atau gambar agar terlihat lebih sempurna dan menarik, seperti foto Wisuda, foto PraWedding, foto di kartu undangan, foto keluarga, foto brosur dan lainnya. Maka diperlukan suatu keterampilan atau pelatihan untuk dapat mengolah atau mengedit foto digital melalui pelatihan - pelatihan olah foto. Adapun software yang digunakan untuk pelatihan untuk mengolah foto digital adalah menggunakan Aplikasi Adobe Photoshop CS6.

Melihat kenyataan yang telah diuraikan, perlu dilakukan suatu kegiatan yang mampu meningkatkan pemahaman dan keterampilan para siswa-siswi dalam mengembangkan kreatifitasnya, khususnya dalam pelatihan olah foto digital dengan menggunakan Aplikasi Adobe Photoshop CS6. Oleh karenanya dilakukan kegiatan pengabdian berupa pelatihan kepada peserta didik dengan Menggunakan Aplikasi Adobe Photoshop CS6 Pada LKP Bintang Mulia Batu Bara Desa Pematang Rambai Kecamatan Nibung Hangus Kabupaten Batu Bara.

\section{METODE}

Metode yang digunakan dalam kegiatan pengabdian masyarakat di LKP Bintang Mulia adalah metode demonstrasi. Metode demonstrasi digunakan untuk menyajikan materi dengan memperagakan melalui penje- 
lasan teori mengenai materi mengolah foto digital dengan Aplikasi Adobe Photoshop CS6. Kemudian dilanjutkan dengan mempraktikan secara langsung pengolahan foto digital kepada para peserta didik LKP Bintang Mulia Batu Bara. Praktek langsung dilakukan pada komputer masing-masing dalam mengimple-mentasikan tool-tool aplikasi Adobe Photoshop CS6.

Kegiatan ini dilaksanakan pada hari Senin sampai Kamis, pada tanggal 16 sampai 19 April 2018, bertempat di LKP Bintang Mulia Batu Bara.

\section{PEMBAHASAN}

Berikut adalah tampilan animasi yang sudah bisa dijalankan.

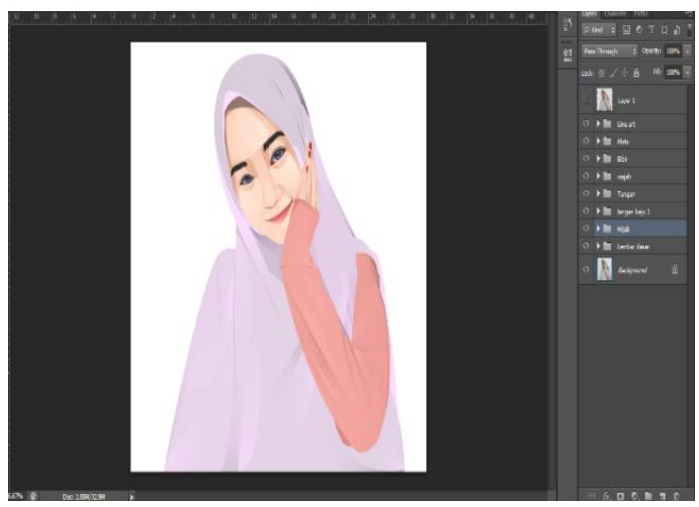

Gambar 1. Tampilan Praktek Animasi

Berdasarkan diskusi yang dilaksanakan setelah pemaparan materi, dapat dilihat bahwa para peserta didik dapat memahami pengembangan media pembelajaran, mampu mengenal fungsi Adobe Photosop CS6, mampu membuat media pembelajaran interktif sesuai dengan bidang/mata pelajaran yang diampu oleh masing-masing peserta didik. Selanjutnya berdasar hasil praktik juga dapat dilihat bahwa para peserta didik mampu mengetahui manfaat aplikasi Adobe Photosop CS6, mengenal panel-panel yang ada pada Adobe Photoshop CS6 serta dan kegunaannya.

Foto Kegiatan
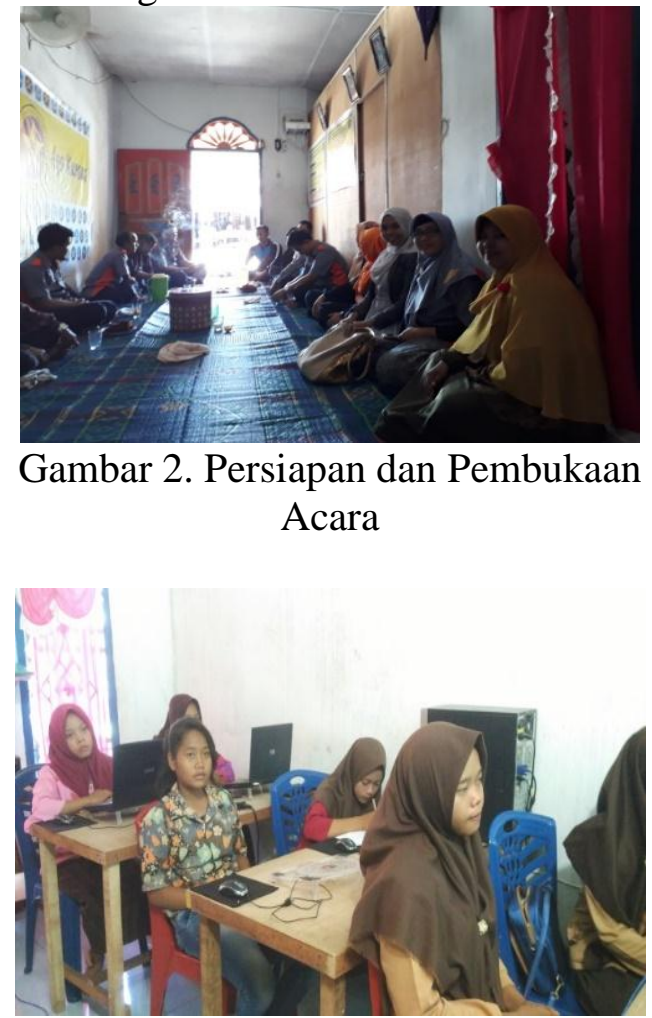

Gambar 3. Foto Siswa yang Hadir

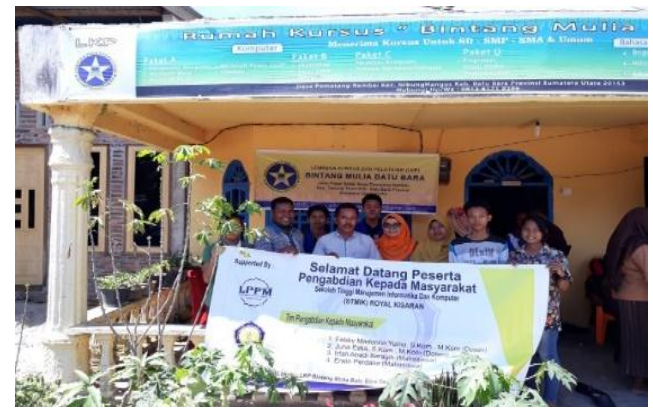

Gambar 4. Foto Bersama Setelah Penutupan 
Jurdimas (Jurnal Pengabdian Kepada Masyarakat) Royal

Vol. 2 No. 1, Jan 2019, hlm. 79 - 82

DOI: https://doi.org/10.33330/jurdimas.v2i1.329

ISSN 2614-7912 (Print)

ISSN 2622-3813 (Online)

Available online at https://jurnal.stmikroyal.ac.id/index.php/jurdimas

\section{SIMPULAN}

Berdasarkan hasil pelaksanaan kegiatan yang telah dilakukan, dapat ditarik kesimpulan sebagai berikut:

1. Dengan adanya pelatihan olah foto digital ini guru dan peserta didik dapat menambah ilmu baru dan teknik baru

2. Dengan adanya pelatihan Animasi ini guru dapat menarik minat belajar peserta didik nantinya.

3. Guru mendapatkan ilmu baru dan teknik baru dalam penyampaian materi pembelajaran.

4. Dengan adanya pelatihan ini guru bisa lebih terampil.

\section{DAFTAR PUSTAKA}

https://www.dee-nesia.com/tutorial-

photoshop-cs6-bahasa-indonesiauntuk -pemula/

Diakses tanggal : 20 Juli 2018

Nindasabrina.2013.https://nindasabrina .wordpress.com/2013/09/26/kom ponen-fungsi-pada-photoshop/.. Diakses tanggal: 20 Juli 2018

Madcoms. 2012.adobe photoshop CS6 untuk pemula. Yogyakarta :Andi.

Diakses tanggal: 29 Juni 2018

Batopie, Rahman. 2015.https ://photoshopdesainlink. files.wordpress.co m./2015/09/ebook-photoshopdesain-free-version.pdf>.

Diakses tanggal: 20 Juli 2018 